\title{
Counterion Effect in Acid Synthesis of Mesoporous Silica Materials
}

\author{
Hong-Ping Lin, ${ }^{\dagger}$ Chia-Pei Kao, ${ }^{\ddagger}$ Chung-Yuan Mou,,$*$ and Shang-Bin Liu ${ }^{\dagger}$ \\ Institute of Atomic and Molecular Sciences Academia Sinica, P.O. Box 23-166, Taipei, Taiwan 106, and \\ Department of Chemistry, National Taiwan University, Taipei, Taiwan 106
}

Received: January 4, 2000; In Final Form: May 29, 2000

\begin{abstract}
Mesoporous silica materials with well-ordered hexagonal structure were synthesized under acidic conditions by using various acid sources HX. The induction time for the formation of mesostructural precipitation increases in the lyotropic series $\mathrm{HNO}_{3}<\mathrm{HBr}<\mathrm{HCl}<\mathrm{H}_{2} \mathrm{SO}_{4}$ under the same acid concentration. The induction rates are analyzed with a micelle-catalyzed reaction scheme. The order in induction time reflects the strength in counterion binding of $\mathrm{X}^{-}$. Nitric acid with the highest binding strength of counterion tends to form very long micelles. We have determined the counterion association constants and found the degree of counterion dissociation under synthetic conditions in solution. The association is only partial during the early morphologysetting stage. $\mathrm{HNO}_{3}$ is a suitable acid source for preparing silica ropes of hierarchical order, consisting of silica fibers formed from parallel nanosized channels. The elongation of the surfactant micelles and shearing flow are the controlling factors in the morphology. Temperature, acid concentration, surfactant chain length, and the addition of polar solvent also have strong influence on the morphology and nanostructure of the mesoporous materials under acidic conditions.
\end{abstract}

\section{Introduction}

Since the discovery of mesoporous aluminosilicate materials, ${ }^{1,2}$ considerable efforts were made to understand their synthesis process in order to control their pore structure and morphology. The process is complicated, involving surfactant self-assembly in solution, mesophases, and silicate condensation reaction. Both thermodynamics and kinetics-limiting processes must be considered.

Mesoporous silica can be synthesized by either the alkaline route $^{1,2}$ or the acidic route..$^{3,4}$ In the alkaline route, surfactant and silicates organize by strong $\mathrm{S}^{+} \mathrm{I}^{-}$electrostatic interaction. The self-organization in alkaline synthesis is better understood as more studies have been performed. ${ }^{5}$ On the other hand, the acidic route is interesting in offering versatile morphologies. In this route, the surfactant/silicate interaction in $\mathrm{S}^{+} \mathrm{X}^{-} \mathrm{I}^{+}$is weaker; thus, it can usually lead to many topological constructions. The use of the weaker interface interaction in acid synthesis permits the more subtle competition of the kinetics of silica condensation and surfactant/silicate assembly. Recent advances in copolymer templating, ${ }^{6}$ mesoporous silica film, ${ }^{7,8}$ gyroids, ${ }^{9}$ fiber, ${ }^{10,11}$ and rope, ${ }^{12,13}$ are based on the acid synthesis route. Also the $\mathrm{pH}$ condition in synthesis is important in the incorporation of other elements into the framework of silica, which is important in applications. However, the physical chemistry in the acidic route is quite different from the alkaline route and it is less understood.

The syntheses of periodical mesoporous silica at $\mathrm{pH}<2$ (the aqueous isoelectric point of silica) is an important advance that needs careful study of its chemistry. ${ }^{14}$ The formation mechanism, composition, and properties are different from those of MCM-

\footnotetext{
* Corresponding author. Fax: 886-2-23636359. Tel: 886-2-23660954 E-mail: cymou@ms.cc.ntu.edu.tw.

Institute of Atomic and Molecular Sciences Academia Sinica.

National Taiwan University.
}

41 materials synthesized under alkaline conditions. ${ }^{4}$ A detailed understanding of the physical chemistry behind its formation would help one toward better control of the structure and morphology in synthesis.

In the acidic route (with $\mathrm{pH}<2$ ), both kinetic and thermodynamic controlling factors need to be considered. First, the acid catalysis speeds up the hydrolysis of silicon alkoxides. Second, the silica species in solution are positively charged as $\equiv \mathrm{SiOH}_{2}{ }^{+}$(denoted as $\mathrm{I}^{+}$). Finally, the siloxane bond condensation rate is kinetically promoted near the micelle surface. The surfactant $\left(\mathrm{S}^{+}\right)$- silica interaction in $\mathrm{S}^{+} \mathrm{X}^{-} \mathrm{I}^{+}$is mediated by the counterion $\mathrm{X}^{-} .4$ The micelle-counterion interaction is in thermodynamic equilibrium. Thus the factors involved in determining the total rate of nanostructure formation are counterion adsorption equilibrium of $\mathrm{X}^{-}$on the micellar surface, surfaceenhanced concentration of $\mathrm{I}^{+}$, and proton-catalyzed silica condensation near the micellar surface.

The role of counterion in the acidic route is that there must exist a mediator ion $\mathrm{X}^{-}$, such as bromide, to be adsorbed on the positively charged surfactant. ${ }^{4}$ Thus Stucky et al. ${ }^{4}$ proposed that the mesoporous materials were formed under acidic condition as the combination of the $\mathrm{S}^{+} \mathrm{X}^{-}$assembly and the silicate species $\mathrm{I}^{+}$. The association of $\mathrm{S}^{+} \mathrm{X}^{-}$determines the structure and morphology of the mesoporous materials. Thus the factors that influence the micellar association of $\mathrm{S}^{+} \mathrm{X}^{-}$would also affect the kinetics of silicate condensation and the resulting structure of mesoporous products.

The theory of micelle-catalyzed chemical reactions has been developed in the past for many chemical reactions. ${ }^{15}$ It applies to reactions taking place predominately on the micellar surface. The enhanced reaction is a result of increase of local concentration of reactants by counterion adsorption or solubilization. ${ }^{16}$ However, the viewpoint of micelle-catalyzed silica condensation reactions has not yet been examined carefully by experiment. In this paper, we are interested in the rate process of silica 
condensation under the influence of cationic surfactant $\mathrm{S}^{+}$and counterion $\mathrm{X}^{-}$. We are interested in the equilibrium binding of $\mathrm{S}^{+}$and $\mathrm{X}^{-}$, and we will examine the variation in rates by changing both the $\mathrm{S}^{+}$and $\mathrm{X}^{-}$species. We then will formulate a kinetic model to explain the rate variations.

Once we understand the elementary kinetics in the surfactant/ silicate system, we would like to correlate further its rich morphologies with kinetic information. We will be especially interested in understanding the relationship of counterion binding and morphology. A "soft" intermediate structure $\left(\mathrm{S}^{+} \mathrm{X}^{-} \mathrm{I}^{+}\right)$is formed under the acidic conditions, which could be influenced by flow field, defect formation, and temperature. Therefore, the acidic route is popular for studying its rich morphology.

To elucidate the connection between nanostructure equilibrium and micrometer-scaled morphology, in this paper we vary many chemical and physical factors, including the nature and concentration of the acid, the shearing flow, temperature, the addition of polar solvent. Here, the hierarchically structured mesoporous materials (millimeter-sized silica ropes and the gyroidal spheres) can be controlled. We will try to rationalize the morphology change in terms of counterion binding.

\section{Experimental Part}

1. Materials. The silica source was tetraethyl orthosilicate (TEOS, 98\%) from Acrôs. The quaternary ammonium surfactant compounds $\mathrm{C}_{n} \mathrm{H}_{2 n+1}\left(\mathrm{CH}_{3}\right)_{3} \mathrm{NX}(n=14-18 ; \mathrm{X}=\mathrm{Cl}$ or $\mathrm{Br})$, were obtained from Aldrich or Merck and used without further purification. Sulfuric acid $\left(\mathrm{H}_{2} \mathrm{SO}_{4}\right)$, hydrochloric acid $(\mathrm{HCl})$, hydrobromic acid $(\mathrm{HBr})$, nitric acid $\left(\mathrm{HNO}_{3}\right)$, and acetate acid $\left(\mathrm{CH}_{3} \mathrm{COOH}\right)$ were obtained from Merck, Acrôs, or Janssen Chimica.

2. Kinetic Measurement. The structure directing agents $\mathrm{C}_{n}$ TMAX $(n=14 \sim 18 ; \mathrm{X}=\mathrm{Cl}$ or $\mathrm{B}$ ) were dissolved in a proper amount of water, and then one added the acid sources to give a clear solution. We used the sodium salts (such as $\mathrm{NaNO}_{3}, \mathrm{NaBr}$, or $\mathrm{NaCl}$ ) to control the ionic strength or adjust the counterion concentration $\left[\mathrm{X}^{-}\right]$. To this solution, the silica source tetraethyl orthosilicate (TEOS) was added under stirring. Because of the strong acidity, the hydrolysis and dissolution of TEOS are much faster than the silica condensation. At this early stage, one obtained a clear solution quickly. Kinetic data were then taken by measuring the induction time $\left(t_{\mathrm{p}}\right)$ for the formation of a white precipitation at different acid or counterion concentration under different temperatures. Here, the concentration of TEOS and surfactant was fixed. The composition of the solution was 1.0 surfactant:5.0 TEOS:764 $\mathrm{H}_{2} \mathrm{O}:(7.0-24.0) \mathrm{H}^{+}:(10.0-$ 25.0) $\mathrm{X}^{-}$. The kinetic data were taken in two cases: one, while keeping $\left[\mathrm{X}^{-}\right]$constant and varying $\left[\mathrm{H}^{+}\right]$, and two, while keeping $\left[\mathrm{H}^{+}\right]$constant and changing $\left[\mathrm{X}^{-}\right]$.

3. Synthesis Procedure. Mesoporous silica millimeter-sized ropes and micrometer-scaled gyroidal spheres were prepared as the procedure described in the kinetic measurement part. But, the gel solution was allowed to further stir for $6-48 \mathrm{~h}$. The gel composition was (in moles): 1 surfactant:(3.0-15.0) TEOS: (10.0-40.0) HX:(500-3000) $\mathrm{H}_{2} \mathrm{O}$. The products were filtered and washed with deioned water and dried at $100{ }^{\circ} \mathrm{C}$. The organic structure directing agents were removed by calcination at 560 ${ }^{\circ} \mathrm{C}$ for $6 \mathrm{~h}$ in air.

4. Characterization. X-ray powder diffraction (XRD) data were collected on a Scintag $\times 1$ diffractometer using $\mathrm{Cu} \mathrm{K} \alpha$ radiation $(\lambda=0.154 \mathrm{~nm})$. The $\mathrm{N}_{2}$ adsorption-desorption isotherms were obtained at $77 \mathrm{~K}$ on a Micromeritics ASAP 2010 apparatus. The scanning electron microscopy (SEM) was taken on an S-800 (Hitachi) operated at an accelerating voltage of 20
$\mathrm{keV}$. The ${ }^{29} \mathrm{Si}$ MAS NMR spectra were recorded with a $400 \mathrm{~s}$ pulse delay on a Bruker MSL 300 NMR spectrometer. The ultrathin transmission electron micrographs (TEM) were made on a Hitachi H-7100 operated at $100 \mathrm{keV}$.

\section{Kinetics of Mesostructure Formation}

In the acid synthesis route of mesoporous silica, the initial micelle formation is fast but the silica condensation is slow. This leads to an experimentally well-defined "induction period" for forming the observable mesophase of surfactant/silicate. Previously, White and co-workers ${ }^{16}$ have studied the slow mesoporous silicate film growth at the air-water interface by X-ray reflectivity. They used the acidic route of synthesis. They found that the mechanism involves two stages - the formation of an organized surfactant layer during the induction period and the subsequent rapid growth of nanostructures, which shows strong X-ray diffraction patterns. ${ }^{16 a}$ However, it is also reported the induction period varies according to solution conditions, and it is not understood. ${ }^{16 \mathrm{~b}}$ It is the purpose of this section to study the kinetics of the induction stage with well-defined solution conditions. We will start from some considerations of mechanism.

According to Huo et al., ${ }^{4}$ the mesostructure formation of the $\mathrm{S}^{+} \mathrm{X}^{-} \mathrm{I}^{+}$mesoporous intermediates is driven by the electrostatic interaction of the positively charged $\mathrm{I}^{+}$and the counterionmediated $\mathrm{S}^{+} \mathrm{X}^{-}$. Thus we write down first the equilibrium of counterion adsorption in solution as eq 1 where the surfactants are associated into micelles. In step 1, the surfactants adsorb the counterions (provided by acid source HX and sodium salts $\mathrm{NaX}$ ) to form the $\mathrm{S}^{+} \mathrm{X}^{-}$micelles.

$$
\sim \oplus+x^{-} \rightleftarrows \sim x^{-}
$$

The hydrolysis and protonation of TEOS are

$$
\begin{gathered}
\equiv \mathrm{Si}-\mathrm{OEt}+\mathrm{H}_{2} \mathrm{O} \rightarrow \equiv \mathrm{Si}-\mathrm{OH}+\mathrm{EtOH} \\
\equiv \mathrm{Si}-\mathrm{OH}+\mathrm{H}^{+} \rightleftarrows \mathrm{Si}-\mathrm{OH}_{2}{ }^{+}
\end{gathered}
$$

The initially dominating condensation reaction occurs on the counterion-adsorbed micelle surface. Thus the rate is catalyzed by the extent of $\mathrm{S}^{+} \mathrm{X}^{-}$formation in eq 1 .

$$
\equiv \mathrm{Si}-\mathrm{OH}_{2}^{+}+\mathrm{HO}-\mathrm{Si} \equiv \stackrel{\sim \mathrm{X}^{-}}{\longrightarrow} \equiv \mathrm{Si}-\mathrm{O}-\mathrm{Si} \equiv+\mathrm{H}_{3} \mathrm{O}^{+}
$$

When enough silica condensation has occurred, the long polysilicate would act as a bridge to bring the cylindrical micelles together to form the mesophase separation, which is the end point of the observed induction period.

One should note that the simple association of surfactant/ counterion in eq 1 is generally assumed in the literature of micelle-catalyzed reaction. ${ }^{15}$ More detailed analysis does not differ much from this assumption. ${ }^{15}$ The association constant $K$ in eq 1 varies with temperature, surfactant, and counterions species. Step 2 is the hydrolysis process of TEOS that is rapidly accomplished under acidic condition. Then the silanol group is protonated in the highly acidic condition. The $\mathrm{S}^{+} \mathrm{X}^{-}$micelles with the counterions $\mathrm{X}^{-}$on the surface have a stronger affinity to combine with the cationic silica species through an electric interaction. Then, $\mathrm{S}^{+} \mathrm{X}^{-}$micelles surface (step 4) catalyzes the condensation reaction of cationic silica species. It has been known $^{17}$ for a long time that the $\mathrm{pH}$ influences strongly the condensation reaction of silicates. The isoelectric point for silica is $\mathrm{pH}=2$. For $\mathrm{pH}<2$, the rate depends on $\left[\mathrm{H}^{+}\right]$linearly. This 
is the result of the equilibrium of eq 3 and the kinetics of eq 4 . As condensation proceeds, the molecular weight of polysilicate increases to become large enough. The highly charged silicate species further combine with the $\mathrm{S}^{+} \mathrm{X}^{-}$micelles and form the mesostructure rapidly. Further exchange of ions and silica condensation in the gel phase would finally produce the gel of the $\mathrm{S}^{+} \mathrm{X}^{-} \mathrm{I}^{0}$ combination.

We assume that step 4 is the rate-controlling step (siloxane condensation) of the mesoporous silica precipitation. According to the assumed formation mechanism and keeping constant the concentration of surfactant and TEOS, we can derive a simple relationship between the induction time $\left(t_{\mathrm{p}}\right)$ of the precipitation and $\left[\mathrm{H}^{+}\right]$and $\left[\mathrm{X}^{-}\right]$(see Appendix) as follows

$$
\begin{aligned}
t_{\mathrm{p}}=\left(1+K\left[\mathrm{X}^{-}\right]\right) / A K\left[\mathrm{H}^{+}\right]\left[\mathrm{X}^{-}\right]= \\
\left(1 / A K\left[\mathrm{H}^{+}\right]\right)\left(1 /\left[\mathrm{X}^{-}\right]\right)+\left(1 / A\left[\mathrm{H}^{+}\right]\right)
\end{aligned}
$$

where $K$ is the association constant of the $\mathrm{X}^{-}$on the $\mathrm{S}^{+}$micelles and, $A$ is a kinetic constant. Or after rearrangement

$$
1 / t_{\mathrm{p}}=A\left[\mathrm{H}^{+}\right]\left\{K\left[\mathrm{X}^{-}\right] /\left(1+K\left[\mathrm{X}^{-}\right]\right)\right.
$$

To test eq 5 , we vary the concentration of $\mathrm{H}^{+}$and $\mathrm{X}^{-}$by using the sodium salts of these counterions to control the ionic strength. The induction time $t_{\mathrm{p}}$ decreases with the concentration of acid and depends on the nature of the acid following the sequence $\mathrm{HNO}_{3}<\mathrm{HBr}<\mathrm{HCl}<\mathrm{H}_{2} \mathrm{SO}_{4}$. Under acidic conditions, the $\mathrm{X}^{-}$concentration is much higher than the surfactant concentration $\left(\left[\mathrm{X}^{-}\right] /[\right.$surfactant $\left.]>10\right)$. To apply eqs (5) and (6), we prepare the solution system by mixing HX and $\mathrm{NaX}$ in two ways: (a) keeping $\left[\mathrm{X}^{-}\right]$constant while varying $\left[\mathrm{H}^{+}\right]$and (b) keeping $\left[\mathrm{H}^{+}\right]$constant while varying $\left[\mathrm{X}^{-}\right]$.

Figure $1 \mathrm{~A}$ shows that the rate $1 / t_{\mathrm{p}}$ increases with the $\left[\mathrm{H}^{+}\right]$in a linear fashion with $\left[\mathrm{X}^{-}\right]=$constant, for $\mathrm{HNO}_{3}, \mathrm{HBr}$, and $\mathrm{HCl}$, as predicted in eq 6 . And $t_{\mathrm{p}}$ show a linear relationship with $1 /\left[\mathrm{X}^{-}\right]$(Figure 1B) as predicted from eq 5. From the linear regression of the lines in Figure $1 \mathrm{~B}$, we obtain the value of the slope/intercept that is equal to the association constant $K$ of the counterion on the surfactant micelles according to eq 5. Figure 2 shows the linear relationship between $t_{\mathrm{p}}$ and $1 /\left[\mathrm{X}^{-}\right]$at various temperatures (Figure 2A) and different chain lengths of the surfactant molecules (Figure 2B). The good linear behaviors in Figures 1 and 2 validate, although not definitely, our kinetic scheme in eq 1 to eq 4 . In other words, the kinetics of silica condensation and counterion adsorption equilibrium are connected through the important $\mathrm{S}^{+} \mathrm{X}^{-}$species. The counterion effect comes as a result of ion-exchange competition on the micellar surface. ${ }^{18}$

Table 1 shows the association constant of the different counterions at various temperatures. The association constant $K$, at the same temperature, is in the order $\mathrm{NO}_{3}{ }^{-}>\mathrm{Br}^{-}>\mathrm{Cl}^{-}$. This order in counterion binding is consistent with the wellknown binding strength Hofmeister series of anions for the cationic surfactant, $\mathrm{NO}_{3}{ }^{-}>\mathrm{Br}^{-}>\mathrm{Cl}^{-}>\mathrm{F}^{-} \sim \mathrm{SO}_{4}{ }^{2-} .{ }^{19}$ For example, recent results obtained from direct EMF measurement of the degree of counterion association also follow the above lyotropic order. ${ }^{20}$ It is also parallel to the effectiveness of the counterions in decreasing the $\mathrm{cmc}$ of the cationic surfactant, which is relative to the binding affinity and follow the series $\mathrm{NO}_{3}{ }^{-}>\mathrm{Br}^{-}>\mathrm{Cl}^{-}>\mathrm{SO}_{4}{ }^{2-} .21$ This order in counterion adsorption was noted early by Stucky and co-workers in their study of the acidic synthesis of mesoporous silica. ${ }^{4}$ However, no quantitative studies were done for the cationic surfactant/ silicate system before.
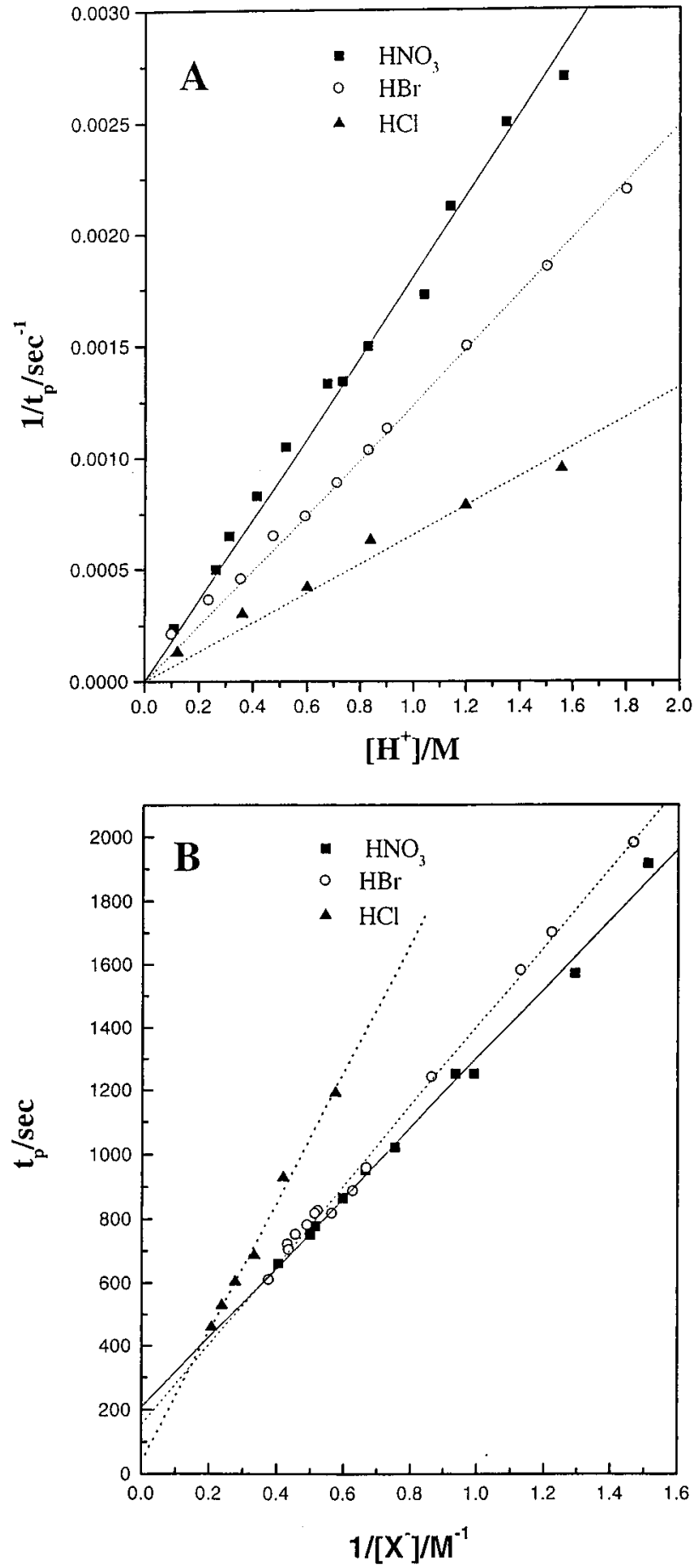

Figure 1. Plots of $1 / t_{\mathrm{p}}$ vs $\left[\mathrm{H}^{+}\right]$and $t_{\mathrm{p}}$ vs $1 /\left[\mathrm{X}^{-}\right]$for $\mathrm{C}_{16} \mathrm{TMAB}-\mathrm{HX}-$ TEOS $-\mathrm{H}_{2} \mathrm{O} ; \mathrm{X}=\mathrm{Cl}^{-}, \mathrm{Br}^{-}, \mathrm{NO}_{3}{ }^{-}$, at a fixed amount of TEOS and $\mathrm{C}_{16}$ TMAB. (A) $1 / t_{\mathrm{p}}$ vs $\left[\mathrm{H}^{+}\right]$plot obtained at constant $\left[\mathrm{X}^{-}\right]\left(\mathrm{NO}_{3}{ }^{-} /\right.$ $\left.\mathrm{C}_{16} \mathrm{TMAB}=21.3 ; \mathrm{Br}^{-} / \mathrm{C}_{16} \mathrm{TMAB}=24.8 ; \mathrm{Cl}^{-} / \mathrm{C}_{16} \mathrm{TMAB}=24.0\right)$. (B) $t_{\mathrm{p}}$ vs $1 /\left[\mathrm{X}^{-}\right]$plot at constant $\left[\mathrm{H}^{+}\right]\left(\mathrm{H}^{+} / \mathrm{C}_{16} \mathrm{TMAB}=7.1\right.$ for $\mathrm{NO}_{3}^{-}$; $\mathrm{H}^{+} / \mathrm{C}_{16} \mathrm{TMAB}=10.6$ for $\mathrm{Br}^{-} ; \mathrm{H}^{+} / \mathrm{C}_{16} \mathrm{TMAB}=24.1$ for $\left.\mathrm{Cl}^{-}\right)$.

From the values of the association constant $K$ in Table 1, one can calculate the degree of counterion dissociation $\alpha$.

$$
\alpha=1 /\left\{1+K\left[\mathrm{X}^{-}\right]\right\}
$$

One can see from Table 1 that the order of dissociation of the monovalent ions follows the order $\mathrm{NO}_{3}{ }^{-}<\mathrm{Br}^{-}<\mathrm{Cl}^{-}$. But the degree of dissociation is much higher than that in simple aqueous micellar solution. For the bromide case at $30{ }^{\circ} \mathrm{C}$, the degree of dissociation is about 0.8 at $\left[\mathrm{Br}^{-}\right]=2.0 \mathrm{M}$, much 

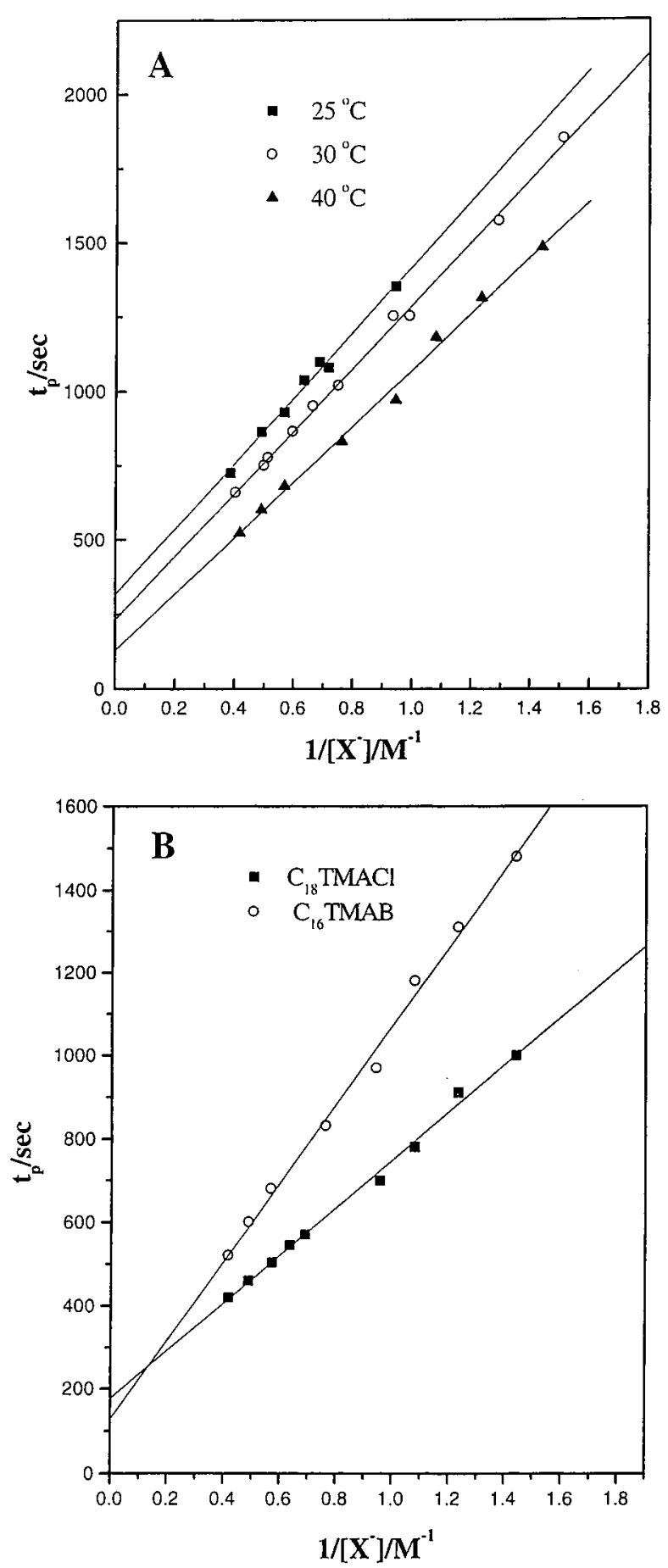

Figure 2. Plots of $t_{\mathrm{p}}$ vs $1 /\left[\mathrm{X}^{-}\right]$for $\mathrm{C}_{n} \mathrm{TMAX}-\mathrm{HNO}_{3}-\mathrm{TEOS}-\mathrm{H}_{2} \mathrm{O}$ compositions at a fixed amount of TEOS at different temperatures. (A) $1 / t_{\mathrm{p}}$ vs $\left[\mathrm{NO}_{3}{ }^{-}\right]$plots of $\mathrm{C}_{16} \mathrm{TMAB}$ obtained at different temperatures. (B) $t_{\mathrm{p}}$ vs $1 /\left[\mathrm{X}^{-}\right]$plots for $\mathrm{C}_{16} \mathrm{TMAB}, \mathrm{C}_{18} \mathrm{TMACl}$ at $40{ }^{\circ} \mathrm{C}$.

higher than the normal value of 0.22 reported for simple $\mathrm{C}_{16}$ TMAB aqueous solution. ${ }^{19}$ For the nitrate case at $30{ }^{\circ} \mathrm{C}$, the degree of dissociation is about 0.69 comparable even to the exceptional anion $\mathrm{OH}^{-}$. For the chloride the counterion association is really small. The reason for such a large difference is that here we are dealing with a solution containing a high concentration of complicated silicate species. The silicate species compete to bind the micelles. Although anionic silicate species are minor in solution, apparently the positively charged $\mathrm{S}^{+}$could still strongly adsorb some anionic silicate such that the degree of association of the counterion $\mathrm{X}^{-}$is not large in the initial stage.
TABLE 1: Association Constants of the Different Counterions $\left(\mathrm{X}^{-}\right)$on the Micelles with Different Chain Lengths at Different Temperatures under Acidic Condition

\begin{tabular}{lccc}
\hline surfactant & counterion & temperature $/{ }^{\circ} \mathrm{C}$ & association constant ${ }^{a}$ \\
\hline$C_{16}$ TMAB & $\mathrm{NO}_{3}{ }^{-}$ & 30 & 0.220 \\
$C_{16}$ TMAB & $\mathrm{Br}^{-}$ & 30 & 0.122 \\
$C_{16}$ TMAB & $\mathrm{Cl}^{-}$ & 30 & 0.018 \\
C $_{16}$ TMAB & $\mathrm{NO}_{3}{ }^{-}$ & 25 & 0.285 \\
$\mathrm{C}_{16}$ TMAB & $\mathrm{NO}_{3}{ }^{-}$ & 40 & 0.136 \\
$\mathrm{C}_{18}$ TMAB & $\mathrm{NO}_{3}{ }^{-}$ & 40 & 0.312
\end{tabular}

${ }^{a}$ The values were calculated from the intercept/slope rations of the $t_{\mathrm{p}}$ vs $1 /\left[\mathrm{X}^{-}\right]$plots in Figures 1 and 2.

However, we note that the adsorbed species $\mathrm{X}^{-}$need only be in a catalytic amount. Once it could start functioning as the catalytic center as in eq 4 , it can continuously help the silica condensation reaction until enough polysilicate bridge ions between cylindrical micelles are produced for the hexagonal phase. The silica condensation reaction continues in the solid phase, after the initial gelation, and further $\mathrm{X}^{-}$condensation would follow to give the final $\mathrm{S}^{+} \mathrm{X}^{-} \mathrm{I}^{0}$ product. Previously we have analyzed the nitrate counterion content in the assynthesized product $\mathrm{S}^{+} \mathrm{X}^{-} \mathrm{I}^{0}$, by elemental analysis. ${ }^{22}$ The ratio of $\mathrm{S}^{+}$to $\mathrm{X}^{-}$is indeed close to 1 . We have just shown that such a stoichiometric ratio is not yet reached when the gel is formed with the morphology already fixed. The simple notion of $\mathrm{S}^{+} \mathrm{X}^{-} \mathrm{I}^{+}$does not imply the counterion content is in a $1: 1$ ratio to the surfactant cation during the crucial initial structuredetermining stage. This is important to realize for a good understanding of the physical chemistry of the formation process of mesoporous silica.

For the counterion nitrate, we also vary the temperature and carbon chain length of the surfactant. Table 1 shows the temperature effect on the association constant $K$ : the higher the temperature, the lower the degree of association. This reflects the fact that counterion adsorption is an exothermic process. Finally, $\mathrm{C}_{18} \mathrm{TMAB}$ surfactant gives an higher counterion association versus $\mathrm{C}_{16} \mathrm{TMAB}$ surfactant as shown in Table 1 . This is the result of hydrophilic-lipophilic balance (HLB); higher hydrophobicity leads to higher counterion condensation and gives better structural ordering in the hexagonal phase. ${ }^{23}$

Equation 4 summaries the silica condensation reaction, which is acid-catalyzed. At low $\mathrm{pH}$ regime, the reaction rate is proportional to $\left[\mathrm{H}^{+}\right] .{ }^{24}$ The sol-gel chemistry is complicated, and more research is needed. Here we make the assumption that silica condensation in eq 4 as catalyzed by $\mathrm{S}^{+} \mathrm{X}^{-}$is the dominating condensation reaction in the early stage. The good fit in Figures 1 and 2 seems to indicate that the assumption is justified.

\section{Structure Control}

Thus, the mesoporous materials with well-ordered hexagonal structure can be readily synthesized from strong acids such as $\mathrm{HCl}, \mathrm{HBr}, \mathrm{HNO}_{3}$, and $\mathrm{H}_{2} \mathrm{SO}_{4}$. Most organic weak acids do not have the ability to protonate the silanol group, and we do not observe the formation of mesoporous materials even at high acid concentration.

Nanostructural Order. Although the kinetic study reported in this paper is for the early stage of silica condensation, the trend in counterion $\mathrm{X}^{-}$adsorption and its catalytic effect on silica condensation does influence the structure of the assynthesized materials. For the strong acids we used, the kinetics and equilibrium of counterion effect should show differences in the structure and morphology of the mesoporous product. First, we report on the extent of silica condensation from ${ }^{29} \mathrm{Si}$ 


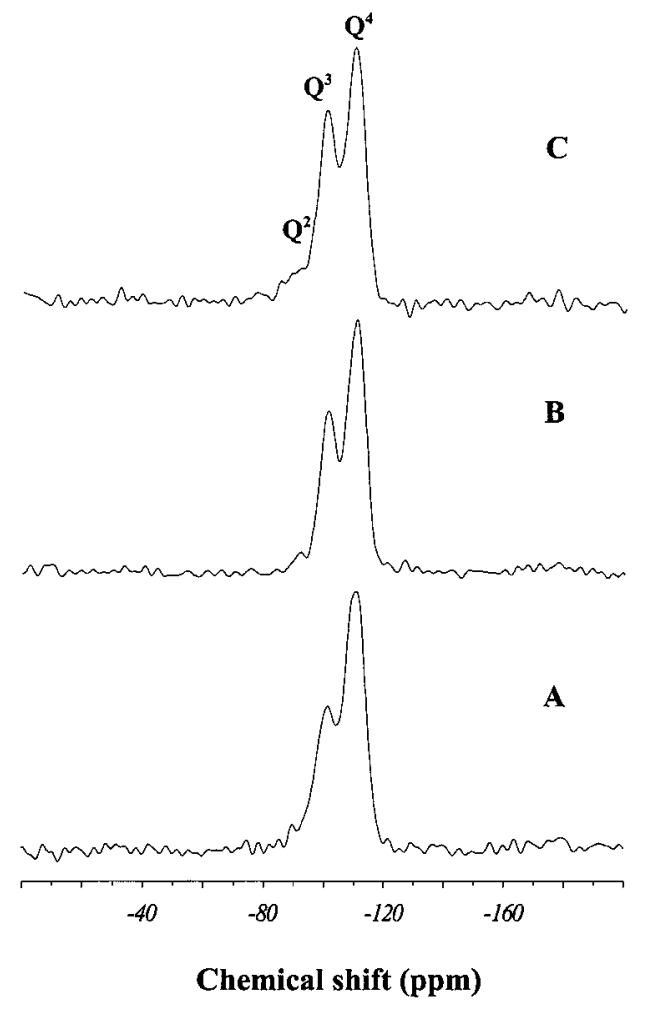

Figure 3. ${ }^{29} \mathrm{Si}$ MAS NMR spectra of the as-synthesized mesoporous materials prepared from $1 \mathrm{C}_{16}$ TMAB:3.0 TEOS:18.7 $\mathrm{HX}: 741 \mathrm{H}_{2} \mathrm{O}$ at $30{ }^{\circ} \mathrm{C}$ for 1 day. (A) $\mathrm{HNO}_{3}\left(\left(Q^{2}+Q^{3}\right) / Q^{4}=0.61\right)$; (B) $\mathrm{HBr}\left(\left(Q^{2}+\right.\right.$ $\left.\left.Q^{3}\right) / Q^{4}=0.76\right)$; (C) $\mathrm{HCl}\left(\left(Q^{2}+Q^{3}\right) / Q^{4}=1.02\right)$.

MAS NMR spectra. If nitrate ions catalyze more silica condensation, the ratio of $\left(Q^{2}+Q^{3}\right) / Q^{4}$ in the ${ }^{29} \mathrm{Si}$ MAS NMR should reflect the trend. Figure 3 shows indeed that the siloxane bond $-\mathrm{Si}-\mathrm{O}-\mathrm{Si}-$ is most complete in the $\mathrm{HNO}_{3}$-treated sample while $\mathrm{HBr}$ is the next and in $\mathrm{HCl}$ the condensation is least complete. The samples in Figure 3 are compared at the same temperature $\left(30^{\circ} \mathrm{C}\right), \mathrm{HX}$ concentration, and the same time (1 day) of reaction.

Second, we report the effect of the acid source on the nanostructure of the mesoporous materials. Figure 4 shows the X-ray diffraction patterns (XRD) of the as-synthesized mesoporous materials from $\mathrm{C}_{16} \mathrm{TMAB}-\mathrm{TEOS}-\mathrm{HX}-\mathrm{H}_{2} \mathrm{O}$ at $30{ }^{\circ} \mathrm{C}$ under the stirring rate of $500 \mathrm{rpm}$ by using different acid source ( $\mathrm{HX}$ $\left.=\mathrm{HCl}, \mathrm{HBr}, \mathrm{HNO}_{3}, \mathrm{H}_{2} \mathrm{SO}_{4}\right)$. One can clearly find that these samples possess the three to four XRD peaks characteristic of hexagonal structure. And the XRD patterns are almost flat between $2 \theta=20-30^{\circ}$, indicating that no amorphous silica particles are formed.

Figure 4D is for the nitric acid case; it gives the best structural order with the sharpest XRD peaks. On closer comparison of Figure $4 A-D$, we can find that the structure order of the assynthesized hexagonal phase follows the order $\mathrm{NO}_{3}{ }^{-}>\mathrm{Br}^{-}>$ $\mathrm{Cl}^{-}>\mathrm{SO}_{4}{ }^{2-}$. The order for the monovalent cations is reasonable, in agreeing with the order in counterion association constants in Table 1. More association of the counterion $\mathrm{X}^{-}$ with surfactants would also lead to the stronger association of the silicates, resulting in better order of the mesoporous product. The nitrate ion gives the strongest counterion association, which neutralizes micellar charge. The stronger charge neutralization would in turn help the formation of more rigid and long micelles and hence better hexagonal structure. ${ }^{25,26}$ The divalent sulfate shows somewhat different behavior, however; it promotes little growth of micelle and leads to poor hexagonal order. ${ }^{27}$ In acid

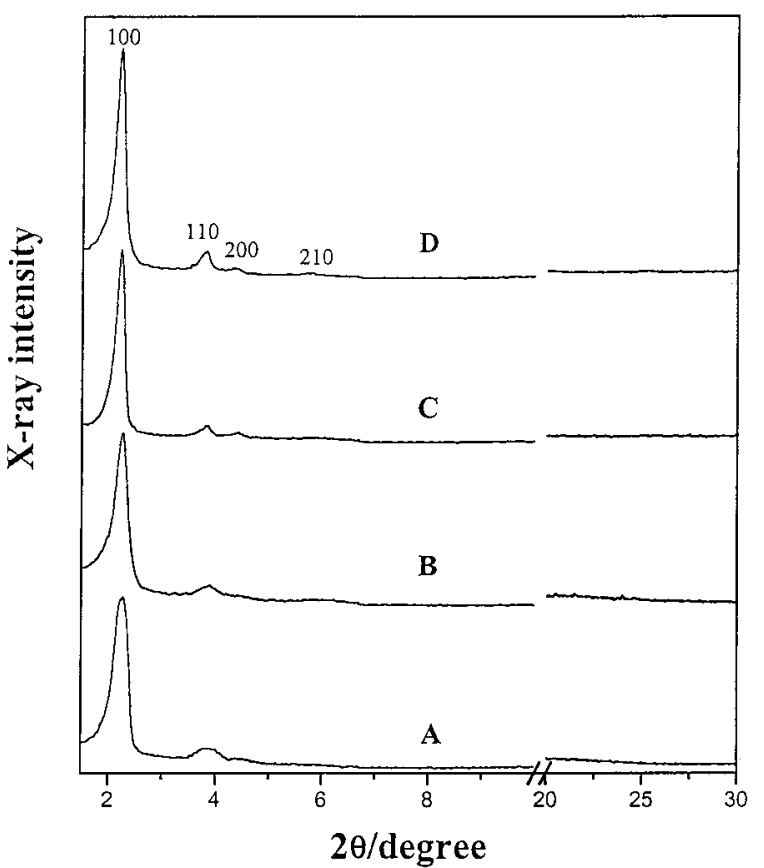

Figure 4. XRD patterns of the as-synthesized materials obtained from $\mathrm{C}_{16} \mathrm{TMAB}-\mathrm{HX}$ systems by using different acid sources. (A) $\mathrm{H}_{2} \mathrm{SO}_{4}$; (B) $\mathrm{HCl}$; (C) $\mathrm{HBr}$; (D) $\mathrm{HNO}_{3}$.

TABLE 2: Physical Properties of the Mesoporous Silica Ropes Synthesized from $\mathrm{C}_{n}$ TMAX-TEOS-HX- $-\mathrm{H}_{2} \mathrm{O}$

\begin{tabular}{|c|c|c|c|c|c|}
\hline $\mathrm{C}_{n} \mathrm{TMAX}^{a}$ & acid & $\begin{array}{c}\text { as-made } \\
d_{100} \\
\text { value/nm }\end{array}$ & $\begin{array}{c}\text { calcined } \\
d_{100} \\
\text { value/nm }\end{array}$ & $\begin{array}{c}\text { BJH } \\
\text { pore }^{b} \\
\text { size/nm }\end{array}$ & $\begin{array}{c}\text { BET } \\
\text { surface } \\
\text { area/cm } / \mathrm{g}\end{array}$ \\
\hline $\mathrm{C}_{16} \mathrm{TMAB}$ & $\mathrm{HCl}$ & 3.98 & 3.43 & 2.13 & 1182 \\
\hline $\mathrm{C}_{16}$ TMAB & $\mathrm{HBr}$ & 3.85 & 3.46 & 2.20 & 1163 \\
\hline $\mathrm{C}_{16} \mathrm{TMAB}$ & $\mathrm{H}_{2} \mathrm{SO}_{4}$ & 4.02 & 3.42 & 2.26 & 1143 \\
\hline $\mathrm{C}_{16}$ TMAB & $\mathrm{HNO}_{3}$ & 4.02 & 3.80 & 2.55 & 1032 \\
\hline $\mathrm{C}_{16} \mathrm{TMACl}$ & $\mathrm{HNO}_{3}$ & 4.03 & 3.85 & 2.54 & 1083 \\
\hline $\mathrm{C}_{18}$ TMACl & $\mathrm{HCl}$ & 4.36 & 3.83 & 2.83 & 1058 \\
\hline $\mathrm{C}_{18} \mathrm{TMACl}$ & $\mathrm{HBr}$ & 4.41 & 4.20 & 3.10 & 982 \\
\hline $\mathrm{C}_{18}$ TMACl & $\mathrm{HNO}_{3}$ & 4.40 & 4.18 & 3.08 & 978 \\
\hline
\end{tabular}

${ }^{a} \mathrm{C}_{18}$ TMAX systems were synthesized at $40{ }^{\circ} \mathrm{C}, \mathrm{C}_{16} \mathrm{TMAX}$ at 30 ${ }^{\circ} \mathrm{C}$. ${ }^{b}$ The values were obtained from the adsorption portion of the $\mathrm{N}_{2}$ adsorption-desorption isotherm.

synthesis, the dominating species is $\mathrm{HSO}_{4}{ }^{-}$at $\mathrm{pH}<1$. Perhaps owing to the weak binding of the highly hydrated species $\mathrm{HSO}_{4}{ }^{-}$ to surfactant, the formation of $\mathrm{S}^{+} \mathrm{X}^{-} \mathrm{I}^{+}$is much inhibited.

In addition to using the surfactant $\mathrm{C}_{16} \mathrm{TMAB}$ as the template, we have also made the mesoporous materials with other surfactants $\mathrm{C}_{n}$ TMAX ( $n \geq 16 ; \mathrm{X}=\mathrm{Cl}$ or $\mathrm{Br}$ ). The physical properties $\left(d_{100}\right.$ value of the as-synthesized and calcined samples, pore size, BET surface area) of these materials are listed in Table 2. Basically, all of these mesoporous materials exhibit large surface area $\left(\sim 1000 \mathrm{~m}^{2} / \mathrm{g}\right)$ and uniform pore size, and the pores are tunable by changing the carbon chain length of surfactant, as those synthesized from basic conditions. The $d$ spacing values increase with carbon chain length of the surfactant. These are well-known. However, comparing the shrinkage of the $d_{100}$ value after calcination at $560{ }^{\circ} \mathrm{C}$, one can find that the shrinking of the $d_{100}$ for the $\mathrm{HNO}_{3}$ sample is only about $0.2 \mathrm{~nm}$, much smaller than those from other acids (about $0.5-0.7 \mathrm{~nm}$ ). This indicates the strongly adsorbed $\mathrm{NO}_{3}{ }^{-}$ion catalyzes more silica condensation and helps the formation of a stronger wall of the hexagonal structure in mesoporous silica. One also expects that $\mathrm{Br}^{-}$binds stronger to $\mathrm{C}_{18} \mathrm{TMA}^{+}$than $\mathrm{C}_{16} \mathrm{TMA}^{+}$, and indeed we find that the shrinkage of $d_{100}$ for $\mathrm{C}_{18} \mathrm{TMAC} / \mathrm{Br}$ after calcination is also smaller at $0.2 \mathrm{~nm}$ (see Table 2). 

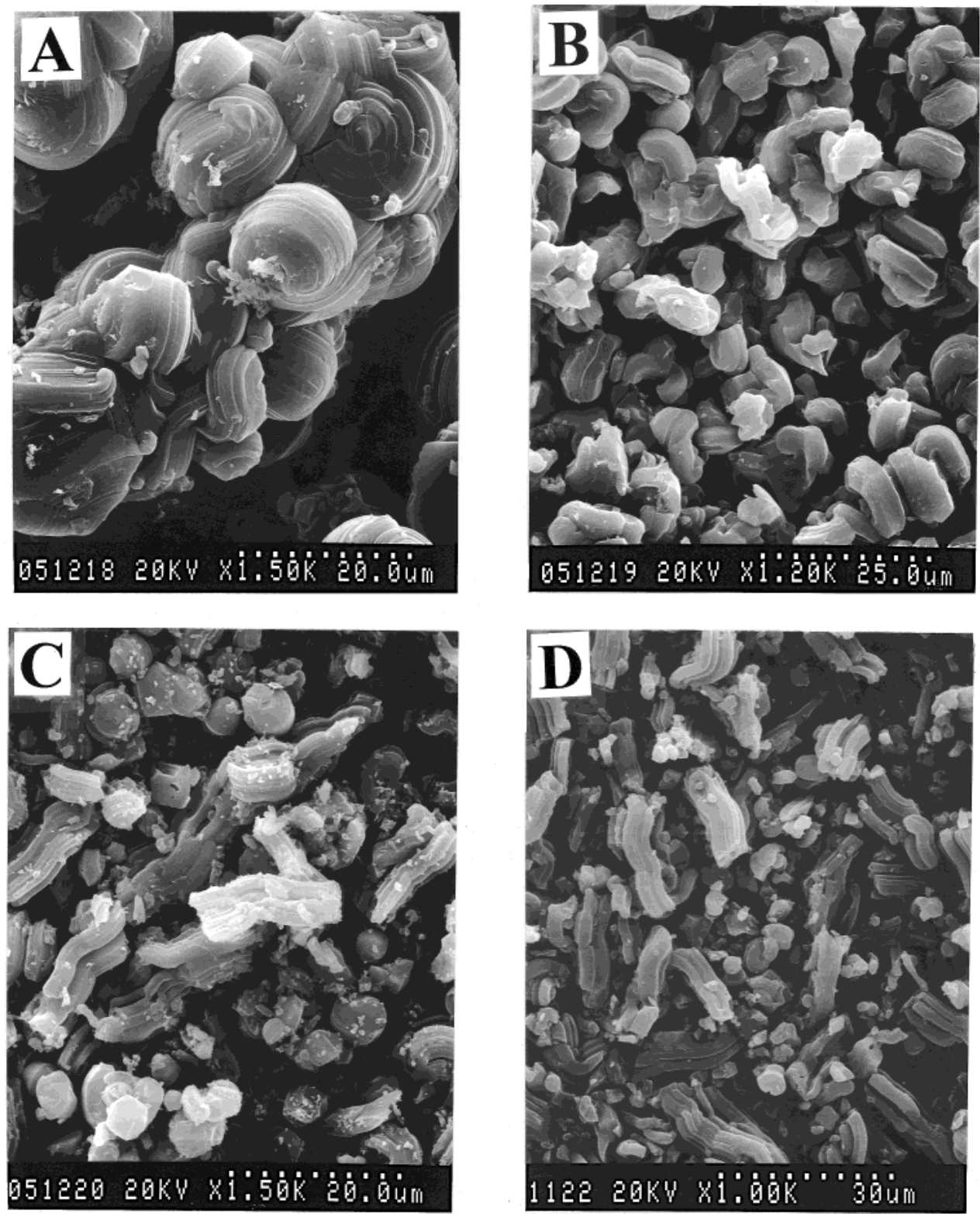

Figure 5. SEM micrographs of the calcined materials obtained from $\mathrm{C}_{16} \mathrm{TMAB}-\mathrm{HX}-\mathrm{TEOS}-\mathrm{H}_{2} \mathrm{O}$ systems by using different acid sources under stirring. All samples are synthesized at $30{ }^{\circ} \mathrm{C}$. (A) $\mathrm{H}_{2} \mathrm{SO}_{4}$; (B) $\mathrm{HCl}$; (C) $\mathrm{HBr}$; (D) $\mathrm{HNO}_{3}$.

Acid HX Altering the Morphology. The morphology of the mesoporous materials synthesized under acidic conditions is rather rich. ${ }^{6-10}$ So, we also examine the morphology of the products obtained from different acid source. Figure 5 A,B shows that with $\mathrm{HCl}$ and $\mathrm{H}_{2} \mathrm{SO}_{4}$ the resulting materials are in micrometer-sized gyroidal spheres, similar to the results of Yang et al. ${ }^{28}$ While using the $\mathrm{HBr}$ and $\mathrm{HNO}_{3}$ as the acid source, the samples are a mixture of the gyroidal spheres and the silica fibers (Figure 5C,D). The $\mathrm{Br}^{-}$and $\mathrm{NO}_{3}^{-}$counterions have stronger binding strength to the surfactant than $\mathrm{Cl}^{-}$or $\mathrm{SO}_{4}^{2-}$ and form more elongated micelles. Then the elongated micelles can be aligned by the shearing flow as the template for the bundles of the silica fibers.

Next, we investigated the effect of temperature. We choose to study the acid system $\mathrm{HNO}_{3}$ for it has the strongest binding tendency. Above room temperature, the effect is more apparent.

Temperature Effect. The surfactant-electrolyte association is sensitive to temperature. Its thermotropic behavior in the formation process of mesoporous silica has been reported. ${ }^{29}$ For our system, we found that the morphological behavior is sensitive to the temperature of assembly. At $32{ }^{\circ} \mathrm{C}$ the morphology of the mesoporous product obtained from the same composition of Figure 5D is completely in gyroidal spheres with different surface textures. When the temperature is decreased to $25{ }^{\circ} \mathrm{C}$, the silica ropes in the millimeter scale are formed (Figure 6B). The yield is high, at about 90\%. A small temperature change can make an obvious morphology difference. This probably reflects a phase-change-like behavior in sphere-to-rod transition, which is sensitive to temperature. ${ }^{4} \mathrm{At}$ $25{ }^{\circ} \mathrm{C}$, the products from using $\mathrm{HCl}$ and $\mathrm{H}_{2} \mathrm{SO}_{4}$ are still in gyroidal spheres, but $\mathrm{HBr}$ promotes a precipitation of the surfactant liquid crystal.

The length and shape of silica ropes are preserved after calcination. The silica ropes consist of the micrometer-sized silica fibers entwined into ropes (Figure 6C), and the crosssection of the fibers are often in a hexagonal shape. ${ }^{13}$ From an ultrathin section TEM micrograph of the silica fiber, one can unambiguously see that the hexagonal-shaped fibers are constituted from the hexagonal-arrayed MCM-41 nanochannels (Figure 6D). Thus we have made silica ropes in second-order hierarchical structure: the nanochannels, the micrometer-scaled fibers, and the millimeter-sized ropes. ${ }^{13}$ 

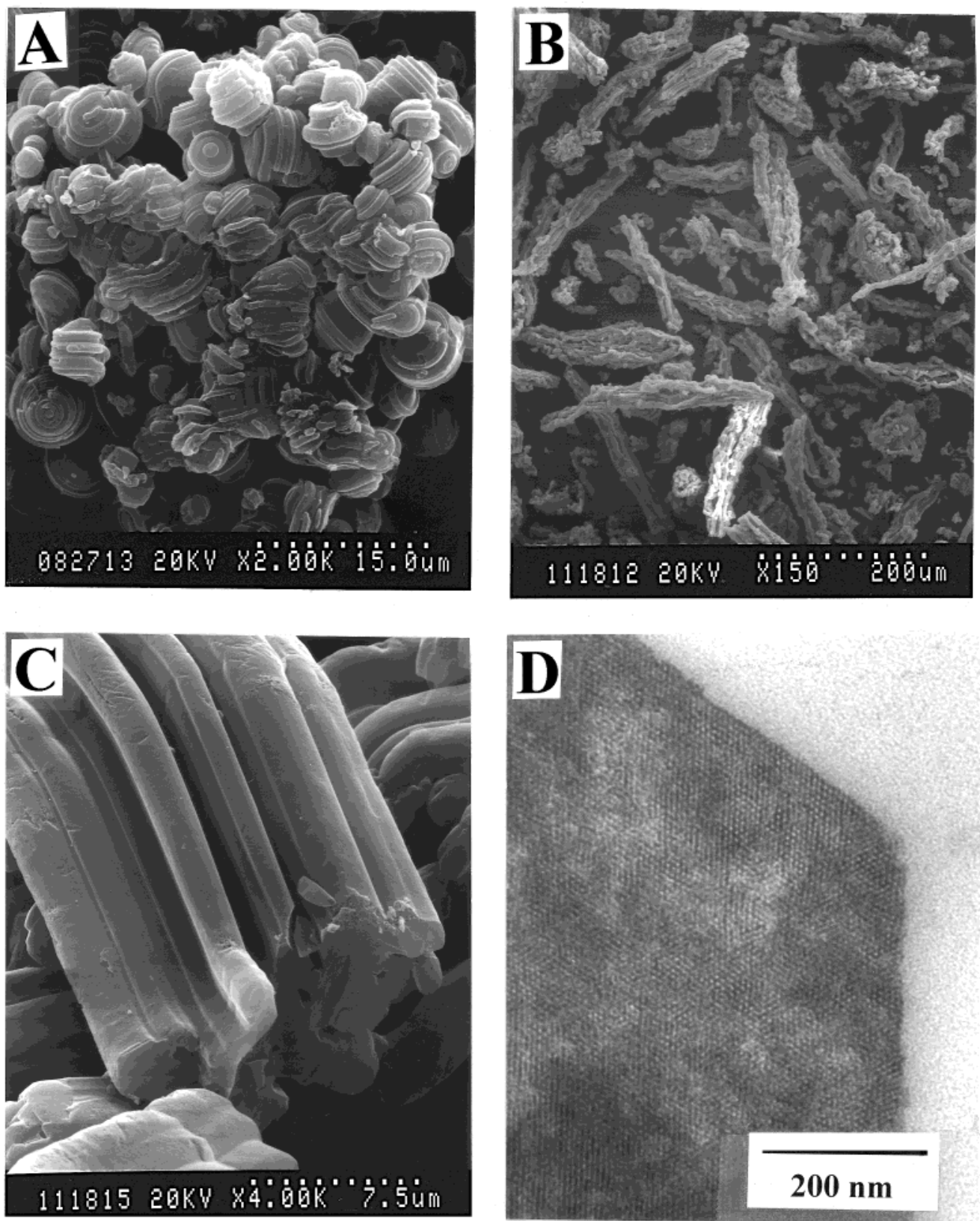

Figure 6. SEM and microtome TEM micrographs of the calcined mesoporous materials prepared from $\mathrm{C}_{16} \mathrm{TMAB}-\mathrm{HNO}_{3}-\mathrm{TEOS}_{-}-\mathrm{H}_{2} \mathrm{O}$ compositions at different temperatures. (A) Gyroidal spheres at $32{ }^{\circ} \mathrm{C}$; (B) silica ropes at $25^{\circ} \mathrm{C}$; (C) the larger magnification of the silica ropes; (D) microtome TEM of the cross section of the silica rope.

Chain Length. Next, we investigate the effect of surfactant chain length on the morphology of product materials. Figure $7 \mathrm{~A}$ is a SEM micrograph of the mesoporous materials obtained from $\mathrm{C}_{18}$ TMAC $-\mathrm{HNO}_{3}-\mathrm{TEOS}-\mathrm{H}_{2} \mathrm{O}$ components. The silica ropes for $\mathrm{C}_{18} \mathrm{TMAB}$ are longer than that of $\mathrm{C}_{16} \mathrm{TMAB}$. The longer chain length of the surfactant leads to higher counterion association, which can promote the formation of the longer rod micelles. It should be noted that the temperature for synthesis of $\mathrm{C}_{18}$ TMAC mesoporous materials is higher $\left(40{ }^{\circ} \mathrm{C}\right)$ than for $\mathrm{C}_{16} \mathrm{TMAB}$. We could not prepare the solution for $\mathrm{C}_{18} \mathrm{TMAB}$ at room temperature, which is lower than its Kraft point. At 25 ${ }^{\circ} \mathrm{C}$, a white $\mathrm{C}_{18}$ TMAC precipitate was formed. In contrast, the sample prepared from $\mathrm{C}_{14} \mathrm{TMAB}$ with less hydrophobilicity is in particle-like morphology even at $20^{\circ} \mathrm{C}$. Therefore, the chain length is also an important chemical factor in determining the morphology.

Shear Flow. When the mesoporous material is synthesized from the same component of Figure 7B under static conditions, the morphology of the mesoporous product is completely in gyroidal spheres, instead of silica fibers (Figure 7A). This might be due to the fact that the shear flow has the ability of aligning the elongated micelles from an entangled wormlike structure into an well-aligned one. And the aligned micellar structure is the necessary template for the formation of the silica ropes. On the other hand, the entangled wormlike structure might be the precursor of the gyroidal spheres.

From the literature on the shearing alignment of the micelles, ${ }^{30,31}$ there must also exist a time scale for aligning the random structure into the bundles. And from our result, we know that the silica condensation rate increases with the concentration of acid. When changing the $\mathrm{HNO}_{3}$ concentration from $\mathrm{HNO}_{3} /$ surfactant $=7.0$ to 20.0, the morphology of the mesoporous materials transforms from silica ropes to gyroidal spheres under a constant shearing flow (Figure 7C). Too much nitric acid did not help the formation of the fibrous form. The result indicates that the silica condensation rate should not be too fast if one 

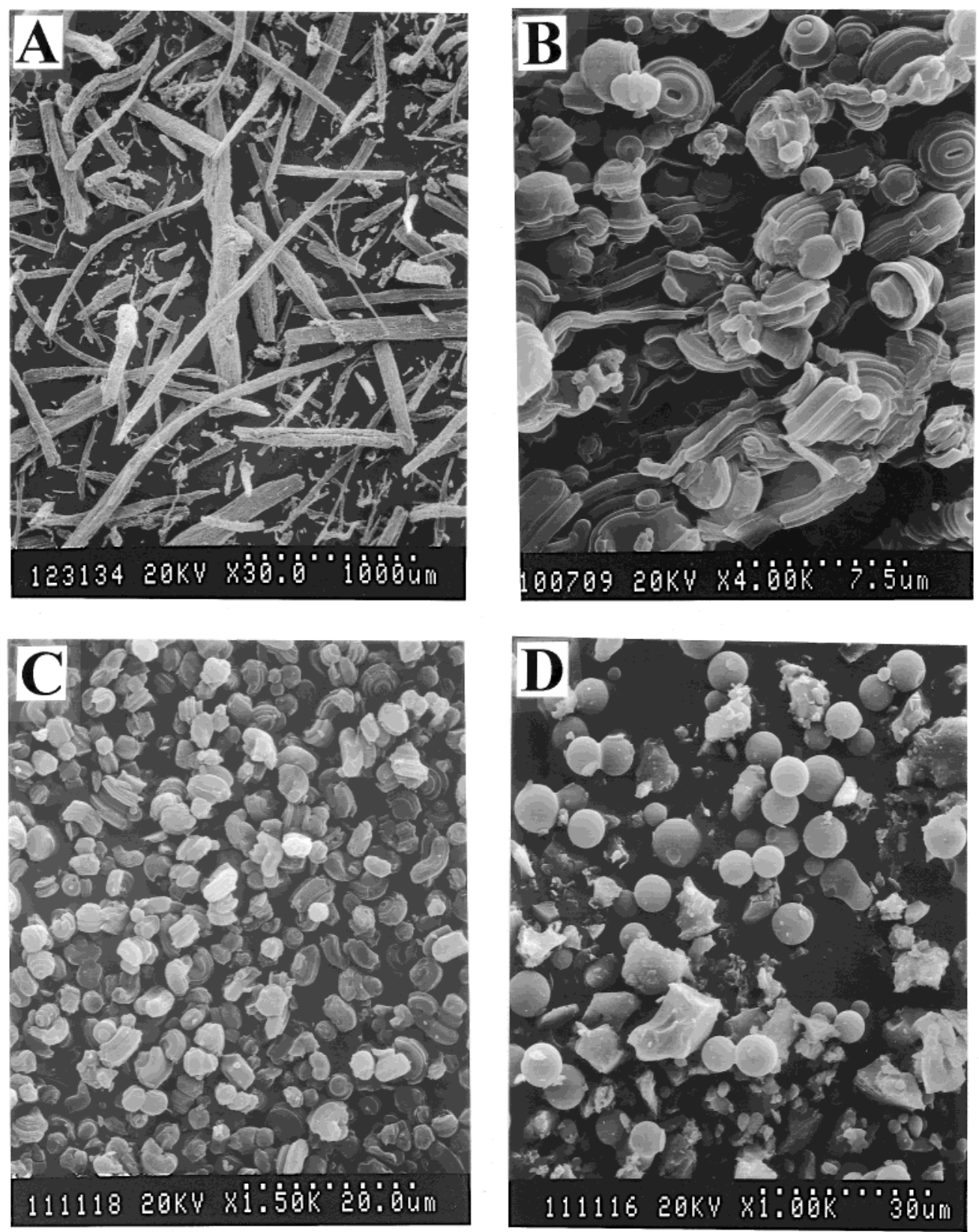

Figure 7. SEM micrographs of the calcined mesoporous samples synthesized from $\mathrm{C}_{18} \mathrm{TMACl}-\mathrm{HNO}_{3}-\mathrm{TEOS}-\mathrm{H}_{2} \mathrm{O}$ compositions at $40{ }^{\circ} \mathrm{C}$ under different reaction compositions and conditions. (A) With stirring; (B) without stirring; (C) at $\mathrm{HNO}_{3} / \mathrm{C}_{18} \mathrm{TMACl}=20.0$; (D) addition of the ethanol $\left(\mathrm{EtOH} / \mathrm{C}_{18} \mathrm{TMACl}=12.0\right)$.

desires the fibrous form. Otherwise the micelles are still in an entangled structure and result in gyroidal spheres.

For elongated micelles, a shearing flow can induce the micelles to arrange parallel to the shearing direction. This behavior is analogous to the flexible polymer. After silica condensation, millimeter-sized silica ropes were formed in high yield. In contrast, short micelles still randomly aligned even under a shear flow. The shorter micellar structure then combined with the silica species and gradually formed the gyroidal spheres. Both the elongated micelles and shearing flow are necessary factors for silica rope formation. Without the shearing flow, the morphology of the mesoporous samples is in gyroidal spheres.

There is much recent interest in the shear-induced phase transition in liquid crystalline surfactant systems, both experimentally ${ }^{30,31}$ and theoretically. ${ }^{32}$ The dynamical instability of a wormlike micelle system under shear flow is a challenging problem. Our surfactant/silicate system may be a good experimental system for more detailed physicochemical studies.
Addition of Polar Solvent. Figure 7D shows the SEM of the mesoporous material synthesized from the same composition of Figure $6 \mathrm{~B}$ with the addition of $\mathrm{EtOH}\left(\mathrm{EtOH} / \mathrm{C}_{16} \mathrm{TMAB}=\right.$ 12.0). The morphology changes to the spheres, some fragments, and the nanostructure becomes less ordered. This result can be accounted for by the fact that the addition of the cosolvent EtOH would decrease the polarity of the solvent and make shorter cylindrical micelles. The shorter cylinders lead to a less ordered mesostructure. ${ }^{23}$ This phenomenon is the same when adding acetone or acetonitrile. ${ }^{33}$ Many elongated micelles are necessary for the formation of silica ropes.

\section{Conclusion}

The acid synthesis route is an important development in mesoporous silica. The weaker interface interaction mediated by the anion $\mathrm{X}^{-}$allows structure and morphology control through the use of various acids HX. It is shown in this paper that the kinetics of formation of mesostructure can be understood 
as a micelle-catalyzed silica condensation reaction. The various $\mathrm{X}^{-}$counterions follow the lyotropic series in their binding ability to the cationic micelles.

Understanding the role and behavior of the counterion effect could help us to control the structure and morphology of the mesoporous silica. Now, we combine the mesostructure formation model and the theoretical considerations of surfactant/ silicate interactions to summarize our results. When using the acids $\mathrm{HCl}$ or $\mathrm{H}_{2} \mathrm{SO}_{4}$, the counterions do not have enough binding strength for the formation of elongated micelles even at low temperatures, and only the gyroidal spheres were formed. The binding strength of $\mathrm{NO}_{3}{ }^{-}$and $\mathrm{Br}^{-}$are high enough to promote the elongated micelles. Thus the silica fibers are obtained by using $\mathrm{HNO}_{3}$ and $\mathrm{HBr}$.

The transition to rodlike micelle and then to hexagonal phase is temperature-sensitive. We observed that the silica ropes could be synthesized from $\mathrm{C}_{16} \mathrm{TMAB}-\mathrm{HNO}_{3}-\mathrm{TEOS}-\mathrm{H}_{2} \mathrm{O}$ at $25^{\circ} \mathrm{C}$. But increasing temperature would decrease the yield and the length of the silica ropes.

Surfactant of longer carbon chain length, corresponding to higher hydrophobilicity, has the stronger tendency to form the elongated micelles. Under the same conditions, the length of the surfactant micelles increases with the chain length. Therefore, the length of the silica ropes of $\mathrm{C}_{18}$ TMAC is longer than that of $\mathrm{C}_{16} \mathrm{TMAB}$. However, the product of the $\mathrm{C}_{14} \mathrm{TMAB} /$ nitrate system is in gyroidal spheres because of the lesser hydrophobilicity of the surfactants. The addition of polar cosolvent modifies the property of solvent and increases the solubility of the surfactant. And the length and size of the surfactant micelles decrease. In addition to these factors altering the surfactant micelles, it should be noted that the entangled micelles could be transformed into well-aligned hexagonal phase under a shearing flow. When the concentration of the acid is high, the silica condensation rate is fast. The silica species combining with entangled micelles would form the gyroidal spheres, instead of silica ropes.

In summary, the surfactant/counterion/silicate association involved in acid synthesis of mesoporous silica is studied in detail. The full understanding of the underlying physical chemistry of the self-assembly and polymerization will help us to better control and design new synthetic schemes.

Acknowledgment. This research is supported by the China Petroleum Co. and the National Science Council of Taiwan (NSC 88-2113-M-002-027).

\section{Appendix}

Here, we show the derivation of reaction rate (eq 5) from the proposed mechanism. It is known, for $\mathrm{pH}<2$, that the silicate species distribution includes a fair amount of positively charged silanols $\mathrm{I}^{+}\left(\equiv \mathrm{Si}-\mathrm{OH}_{2}{ }^{+}\right)$and the condensation reaction is linear in $\left[\mathrm{H}^{+}\right] .{ }^{17}$ One can write the equilibrium constant $K_{3}$ for eq 3 as

$$
K_{3}=\left[\equiv \mathrm{Si}-\mathrm{OH}_{2}^{+}\right] /\left\{\left[\mathrm{H}^{+}\right][\equiv \mathrm{Si}-\mathrm{OH}]\right.
$$

and the equilibrium for eq 1 as

$$
K=\left[\mathrm{S}^{+} \mathrm{X}^{-}\right] /\left[\mathrm{S}^{+}\right]\left[\mathrm{X}^{-}\right]
$$

The catalyzed reaction rate for eq 4 can be written as

$$
\mathrm{d}[\mathrm{p}] / \mathrm{d} t=k_{4}\left[\equiv \mathrm{Si}-\mathrm{OH}_{2}^{+}\right][\equiv \mathrm{Si}-\mathrm{OH}]\left[\mathrm{S}^{+} \mathrm{X}^{-}\right]
$$

As we know, $\equiv \mathrm{Si}-\mathrm{OH}$ species are from the hydrolysis of TEOS, which is formed rapidly. Under our conditions, the TEOS concentration is fixed. Hence, the concentration $[\equiv \mathrm{Si}-\mathrm{OH}]$ is a constant and together with eq A1, eq A3 can be simplified as

$$
\mathrm{d}[\mathrm{p}] / \mathrm{d} t=\mathrm{C}\left[\mathrm{H}^{+}\right]\left[\mathrm{S}^{+} \mathrm{X}^{-}\right]
$$

where $\mathrm{C}$ is a constant.

The mass conservation between $\mathrm{S}^{+}$and $\mathrm{S}^{+} \mathrm{X}^{-}$gives

$$
\left[\mathrm{S}^{+}\right]_{0}=\left[\mathrm{S}^{+}\right]+\left[\mathrm{S}^{+} \mathrm{X}^{-}\right]
$$

$\left[\mathrm{S}^{+}\right]_{0}$ is the added surfactant concentration, which is kept constant in our experiment. With the thermodynamic equilibrium between $\mathrm{S}^{+} \mathrm{X}^{-}, \mathrm{X}^{-}$, and $\mathrm{S}^{+}$given by eq $\mathrm{A} 2$, we obtain the following equation

$$
\left[\mathrm{S}^{+} \mathrm{X}^{-}\right]=\left[\mathrm{S}^{+}\right]_{0} K\left[\mathrm{X}^{-}\right] /\left\{1+K\left[\mathrm{X}^{-}\right]\right\}
$$

Substituting eq A6 into eq A4, one has

$$
\mathrm{d}[\mathrm{p}] / \mathrm{d} t=C\left[\mathrm{~S}^{+}\right]_{0}\left[\mathrm{H}^{+}\right]\left\{K\left[\mathrm{X}^{-}\right] /\left\{1+K\left[\mathrm{X}^{-}\right]\right\}\right\}
$$

And integration of eq A7 leads to

$$
[\mathrm{p}]_{\mathrm{tp}}=C[\mathrm{~S}]_{0}\left[\mathrm{H}^{+}\right]\left(K\left[\mathrm{X}^{-}\right] / 1+K\left[\mathrm{X}^{-}\right]\right) t_{\mathrm{p}}
$$

$[\mathrm{p}]_{\mathrm{tp}}$ is the critical gel precipitation point, which is a constant. Equation A7 is now reorganized as eq 5

$$
t_{\mathrm{p}}=\left(1+K\left[\mathrm{X}^{-}\right]\right) / A K\left[\mathrm{H}^{+}\right]\left[\mathrm{X}^{-}\right]
$$

with $A$ being an experimental constant.

\section{References and Notes}

(1) (a) Kresge, C. T.; Leonowicz, M. E.; Roth, W. J.; Vartuli, J. C.; Beck, J. S. Nature 1992, 359, 710. (b) Beck, J. S.; Vartuli, J. C.; Roth, W. J.; Leonowicz, M. E.; Kresge, C. T.; Schmitt, K. D.; Chu, C. T.-W.; Olson, D. H.; Sheppard, E. W.; Higgins, S. B.; Schlenker, J. L. J. Am. Chem. Soc. 1992, 114, 10834

(2) Huo, Q.; Margoleses, S. I.; Stucky, G. D. Chem. Mater. 1996, 8, 1147.

(3) Huo, Q.; Margoleses, S. I.; Ciesla, U.; Feng, P.; Gier, D. E.; Sieger, P.; Chmelka, B. F.; Leon, R.; Petroff, P. M.; Schuth, F.; Stucky, G. D. Nature 1994, 368, 317.

(4) Huo, Q.; Margoleses, S. I.; Ciesla, U.; Demuth, D. G.; Feng, P.; Gier, D. E.; Sieger, P.; Chmelka, B. F.; Schuth, F.; Stucky, G. D. Chem. Mater. 1994, 6, 1176.

(5) Firouzi, A.; Atef, F.; Oetli, A. G.; Stcky, G. D.; Chmelka, B. F. J. Am. Chem. Soc. 1997, 119, 3596.

(6) Yang, P.; Zhao, D.; Chmelka, B. F.; Stucky, G. D. Chem. Mater. 1998, 10, 2033.

(7) (a) Yang, H.; Coombs, N.; Sokolov, I.; Ozin, G. A. Nature 1996, 381, 589. (b) Yang, H.; Kuperman, A.; Coombs, N.; Mamiche-Afara, S.; Ozin, G. A. Nature 1996, 379, 703.

(8) Ryoo, R.; Ko, C. H.; Cho, S. J.; Kim, J. M. J. Phys. Chem. B 1997, 101,10610

(9) (a) Yang, H.; Coombs, N.; Ozin, G. A. Nature 1997, 386, 692. (b) Ozin, G. A.; Yang, H.; Sokolov, I.; Coombs, N. Adv. Mater. 1997, 9, 662.

(10) Schacht, S.; Huo, Q.; Voigt-Martin, I. G.; Stucky, G. D.; Schüth, F. Science 1996, 273, 768 .

(11) Huo, Q.; Zhao, D.; Feng, J.; Weston, K.; Buratto, S. K. Stucky, G. D.; Schacht, S.; Schüth, F. Adv. Mater. 1997, 9, 974.

(12) Schmidt-Winkel, P.; Yang, P.; Margoles, D. I.; Chmelka, B. F.; Stucky, G. D. Adv. Mater. 1999, 11, 303.

(13) Lin, H. P.; Liu, S. B.; Mou, C. Y. and Tang, T. Y. Chem. Commun. 1999, 583.

(14) Zhao, D.; Yang, P.; Huo, Q.; Chmelka, B. F.; Stucky, G. D. Curr. Opin. Solid State Mater Sci. 1998, 3, 111.

(15) Fendler, J. H.; Fendler, E. J. Catalysis in Micellar and Macromolecular Systems; Academic Press: New York, 1975. 
(16) (a) Brown, A.; Holt, S. S. A.; Dam, T.; Trau, M.; White, J. W. Langmuir 1997, 13, 6363. (b) Brown, A. S.; Holt, S. A.; Reynolds, P. A.; Penfold, J.; White, J. W. Langmuir 1998, 14, 5532. (c) Holt, S. A.; Foran, G. J.; White, J. W. Langmuir 1999, 15, 2540.

(17) Okkerse, C. Porous Silica. In Physical and Chemical Aspects of Adsorption and Catalysts; Linsen, B. G., Ed.; Academic Press: New York, 1970.

(18) (a) Munoz, M.; Rodriguez, A.; del Mar Graciani, M.; M. Moya, L. Langmuir 1999, 15, 2254. (b) Quina, F. H.; Chaimovich, H. J. Phys. Chem. 1979, $83,1844,1851$.

(19) Rubingh, D. N.; Holland, P. M. Cationic Surfactant: Physical Chemistry; In Surfactant Science Series 37; Marcel Dekker: New York, 1991.

(20) Gaillon, L.; Lelievere, J.; Gaboriaud, R. J. Colloid Interface. Sci. 1999, 213, 287.

(21) Gamboa, C.; Rios, H.; Sepulveda, L. J. Phys. Chem. 1989, 93, 5540. Tanford, C. The Hydrophobic Effect: Formation of Micelles and Biological Membranes; Wiley: New York, 1980.

(22) Lin, H. P.; Liu, S. B.; Mou, C. Y. Chem. Lett. 1999, 12, 1341.
(23) (a) Lin, H. P.; Cheng, Y. R.; Liu, S. B.; Mou, C. Y. J. Mater Chem. 1999, 9, 1197. (b) Lin, H. P.; Cheng, Soofin; Mou, C. Y. Micropor. Mater. 1997, 10, 111-121.

(24) Iler, R. K. The Chemistry of Silica; John Wiley: New York, 1979.

(25) Evans, D. F.; Wennerstrom, H. The Colloid Domain; VCH: New York, 1994

(26) Israelachvili, J. N.; Mitchell, D. J.; Ninham, B. W. J. Chem. Soc. Faraday Trans. B 1976, 72, 1525.

(27) Yang, H.; Vovk, G.; Coombs, N.; Sokolov, I.; Ozin,G. A. J. Mater. Chem. 1998, 8, 743.

(28) Ogawa, M.; Igarashi, T.; Kuroda, K. Chem. Mater. 1999, 10, 1382.

(29) Boltenhagen, P.; Hu, Y.; Matthys, E. F.; Pine, D. J. Europhys. Lett. 1997, 38, 389.

(30) Boltenhagen, P.; Hu, Y.; Matthys, E. F.; Pine, D. J. Phys. Rev. Lett. 1997, 79, 2359.

(31) Olmsed, P. D.; Lu, C. Y. D. Farady Discuss. 1999, 112, 183.

(32) Cheng, Y. R.; Lin, H. P.; Mou, C. Y. Phys. Chem. Chem. Phys. 1999, 21, 5138 . 